\title{
Untangling the Role of the Capping Agent in Nanocatalysis: Recent Advances and Perspectives
}

\author{
Sebastiano Campisi *, Marco Schiavoni, Carine Edith Chan-Thaw and Alberto Villa * \\ Dipartimento di Chimica, Università degli Studi di Milano, via Golgi 19, 20133 Milano, Italy; \\ marco.schiavoni@unimi.it (M.S.); carine.chanthaw@unimi.it (C.E.C.-T.) \\ * Correspondence: sebastiano.campisi@unimi.it (S.C.); alberto.villa@unimi.it (A.V.); \\ Tel.: +39-02-5031-4056 (S.C.); +39-02-5031-4351 (A.V.)
}

Academic Editor: Keith Hohn

Received: 28 October 2016; Accepted: 23 November 2016; Published: 27 November 2016

\begin{abstract}
Capping agents (organic ligands, polymers, surfactants, etc.) are a basic component in the synthesis of metal nanoparticles with controlled size and well-defined shape. However, their influence on the performances of nanoparticle-based catalysts is multifaceted and controversial. Indeed, capping agent can act as a "poison", limiting the accessibility of active sites, as well as a "promoter", producing improved yields and unpredicted selectivity control. These effects can be ascribed to the creation of a metal-ligand interphase, whose unique properties are responsible for the catalytic behavior. Therefore, understanding the structure of this interphase is of prime interest for the optimization of tailored nanocatalyst design. This review provides an overview of the interfacial key features affecting the catalytic performances and details a selection of related literature examples. Furthermore, we highlight critical points necessary for the design of highly selective and active catalysts with surface and interphase control.
\end{abstract}

Keywords: heterogeneous catalysis; metal nanoparticles; active site; capping agent; interfaces; promoter; poison; modifier

\section{Introduction}

In the last decades, the interest in metallic nanoparticles (MNPs) has experienced a continuous growth, sustained by the potential application of these MNPs in several fields [1-4]. Owing to their large surface-to-volume ratio, nanosized particles have been successfully employed in the area of catalysis [5-8]. Nanocatalysis combines the advantages of easy separation, handling and reuse, typical of heterogeneous catalysts, and the benefits of homogeneous catalysis, namely high selectivity and efficiency [9]. Nevertheless, understanding the structure-reactivity relationship at atomistic level still represents a major challenge in the ratio design of nanocatalysts [10-13].

Unsupported metal nanoparticles with well-defined surface structure and clean exposed facets are a simplified model for theoretical studies. However, the transfer from computational approaches and real catalysts is still a challenge. Indeed, because of their high-dispersed state, metal nanoparticles in solution tend to spontaneously agglomerate and coagulate, therefore need to be stabilized [4]. The stabilization of MNPs can be achieved by immobilization on a support or by wrapping them in an organic ligand shell [13-15].

Surfactants [16], small ligands [17], polymers [18], dendrimers [19], cyclodextrins [20] and polysaccharides [21] have been successfully utilized as capping agent (Figure 1). Besides preventing nanoparticles agglomeration, the modification of metal surface by organic ligands is a useful tool for increasing the compatibility with another phase or introducing additional functionalities [22]. Moreover, in the case of supported metal nanoparticles, the capping agent can facilitate the anchoring onto the support resulting in a high metal dispersion [23]. 

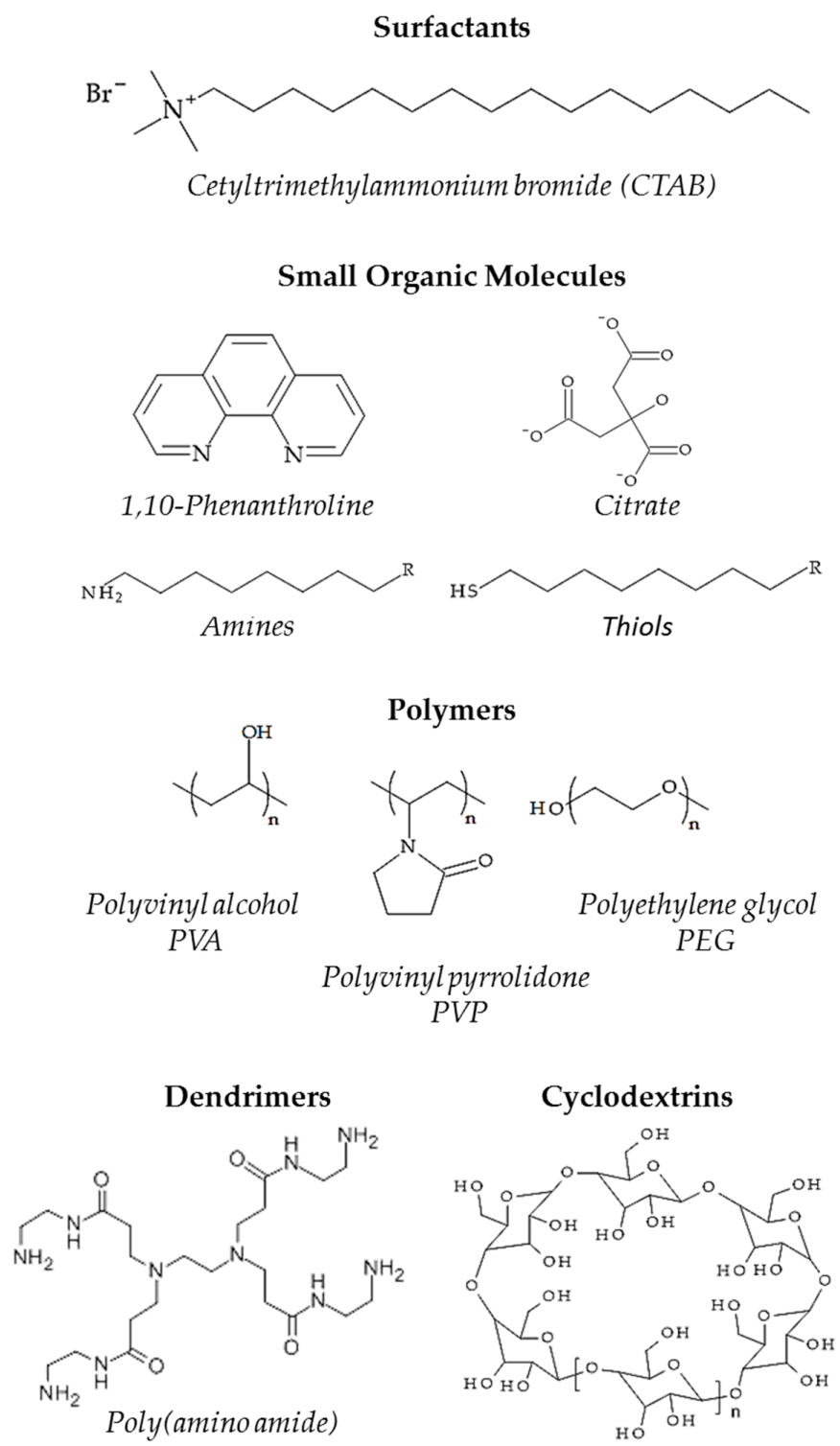

Figure 1. Representative capping agents used in metal nanoparticle synthesis.

From a catalytic point of view, the presence of capping agents is considered to have an adverse impact on the performances of MNPs, mainly because of the hindered access of reactants to catalyst surface [24,25]. Different strategies such as thermal annealing [26], solvent washing [27] and UV-ozone (UVO) irradiation [28], have been utilized to remove the ligand from particle surface. However, most of them resulted in affecting particle size, shape and stability [25].

Recently, an increasing number of studies disclosed an unexpected potential of capping agents, which might act as promoters and/or selectivity modifiers in various liquid-phase reactions [29]. This complex behaviour derives from the creation of a metal-ligand interphase, where electronic and steric factors lead to a sensitive modification of the local environment [30]. The extent of these effects is a function of the coverage degree, the composition, the spatial arrangement and the specific interactions of capping agents with metal surface and other chemical species (reactants, solvents, etc.). Therefore, a characterization of metal-ligand interphase is the starting point for the design of MNPs, based on the type and amount of the capping agent.

In this review, we focus on the current knowledge of electronic and geometric features correlated to the metal-ligand interphase and on the implications of the latter to catalytic performances. 
Recent progresses in understanding the role of capping agent will be summarized by reporting selected examples from the literature.

\section{The Metal-Ligand Interphase and Its Impact on the Catalytic Performances}

In heterogeneous catalysis, almost all phenomena involved in the catalytic cycle take place in the region between the catalyst surface and the reaction medium. Therefore, describing the interface at the nanoscale is necessary for elucidating kinetic mechanisms and the nature of the active sites. The presence of an organic shell generated by capping agents on the nanoparticle surface introduces two different interfaces: the metal-ligand interface and the ligand-solution interface (Figure 2) [31]. Borders between these interfaces are not well defined, but they are intermixed in a transition zone defined as the metal-ligand interphase [31]. The morphology and the energetics of the latter rule the overall kinetics of the catalytic process by altering the local environment around the active sites (i.e., the access to the active sites, the orientation of reactants), and by mediating the interactions with the surrounding environment (i.e., wettability properties and, in the case of supported NPs, the metal-support interactions [32]).

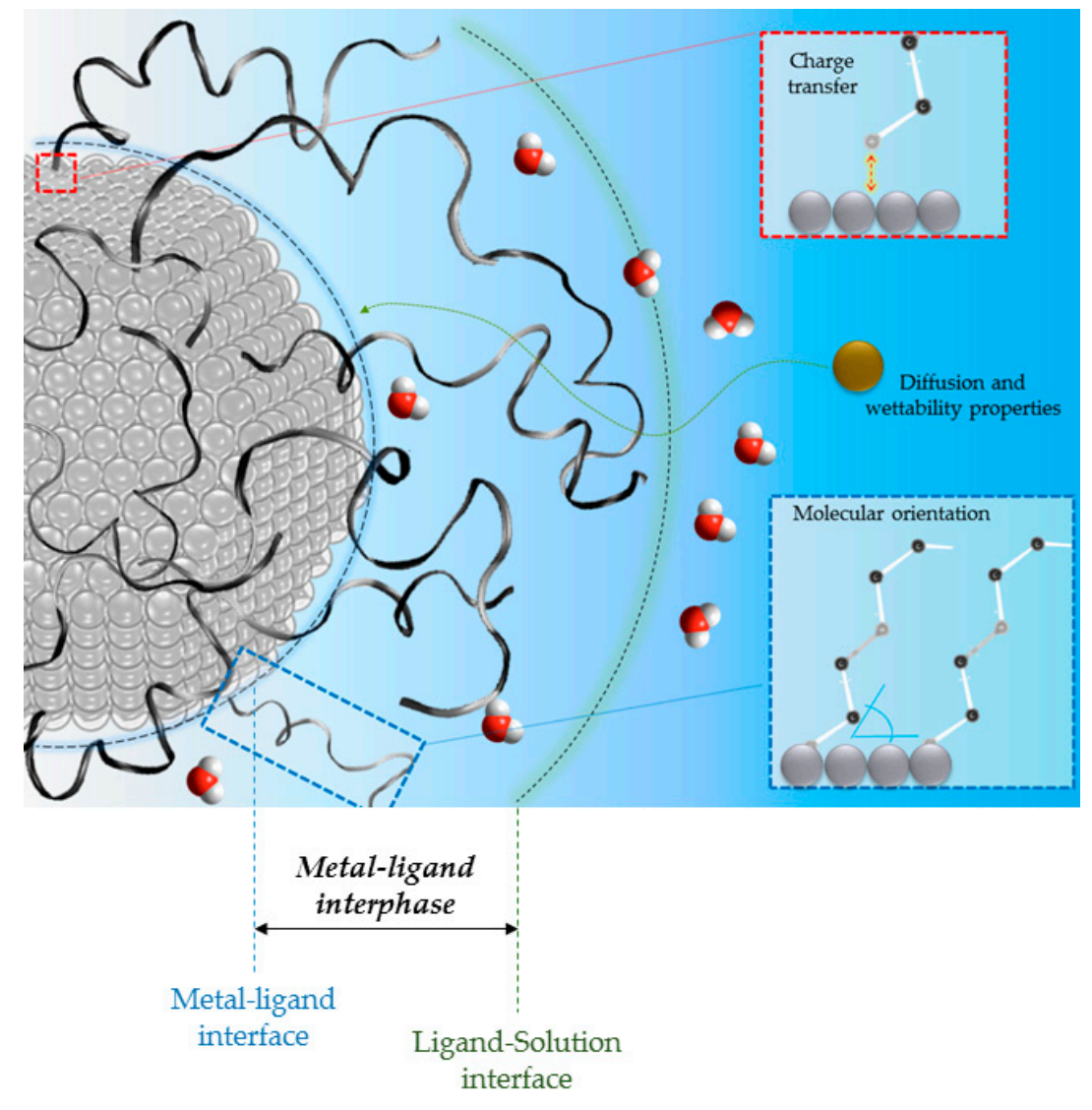

Figure 2. The metal-ligand interphase.

The metal ligand interphase can affect the activity and selectivity according to different mechanisms: charge transfer, selective blocking, chiral modification, molecular recognition, adsorption geometry control and steric hindrance [33].

The most important part of the literature focuses on the synthesis of organic capped metal nanoparticles. However, limited efforts have been devoted to understand, describe and control the interphase between metal nanoparticles and organic capping agents, and thus rationalize the final effect on the catalytic processes. 


\subsection{Chemical Bonding and Electronic Structure at the Metal-Ligand Interphase}

In heterogeneous catalytic cycle (adsorption, adsorbate lateral diffusion, surface reaction, desorption), each step involves bond-making and bond-breaking events, which necessarily refers to the electronic properties of the catalysts and the reactants [34-37]. The combination of theoretical models and experimental observations confirmed the central role of the electronic structure effect in heterogeneous catalysis [10,38].

Therefore, changes in the energetics of the metal surface affect its reactivity and catalytic properties. In this respect, the adsorption of capping agent molecules induces a perturbation in the metal nanoparticle electronic structure, whose extent is a function of the interaction strength [39].

In particular, after the interaction between the discrete molecular orbitals of the ligand and the delocalized electronic states of the metal, a shift on the position of the Fermi level $\left(E_{f}\right)$ for the metal nanoparticle is produced (Figure 3). This effect is due to charging effects and to the modification of the local charge density, which in turn alters the surface potential. The result is the instauration of an interfacial potential, which includes the contribution of the charge-transfer as well as of the polarization at the interface [40-42].

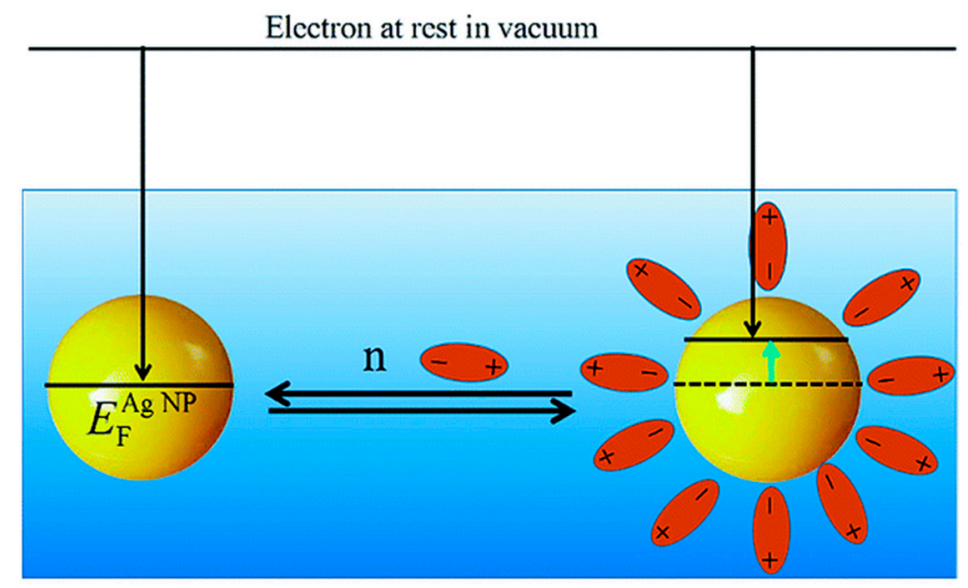

Figure 3. The Fermi level shift of metal nanoparticles Reproduced from ref. [39] with permission of The Royal Society of Chemistry.

The polarization effects are present in the metal-ligand interface. They can be attributed to the orientation of permanent dipole moments (in the case of polar ligands) or to the induction of a dipole layer at the interface [39]. These effects can follow two possible mechanisms: (a) the Pauli repulsion (or pillow effect) associated with the repulsive interaction between the metal electrons and the core-electrons of adsorbed molecules [43]; and (b) the image charge effect [44]. In any case, the contribution of polarization effects is negligible compared to the charge transfer (CT).

The charge transfer derives from the electron coupling between $d$ orbitals of the metal and the ligand energy levels. The strength of this interaction depends on the relative position of HOMO and LUMO orbitals of the ligand in respect to the metal Fermi level and can be interpreted invoking the Hard-Soft Acid-Base (HSAB) theory [45]. According to that, the metal, which in the zero oxidation state is a soft acid, binds preferentially to a ligand with a softer base character. This principle has been demonstrated by monitoring the optical properties of Au nanoparticles capped with different ligands, namely dodecanol, dodecylamine and dodecylthiol [46]. The modified electron density and charge distribution on the metal surface result in a spectral shift in the maximum of localized surface plasmon resonance (LSPR) band, whose extent reflects the strength of the interaction [46]. It has been observed that the revealed trend in spectral shifts followed the order Au-S (soft-soft) $>\mathrm{Au}-\mathrm{N}$ (soft-borderline) $>\mathrm{Au}-\mathrm{O}$ (soft-hard) interaction, in accordance with HSAB theory. The strong interaction between $\mathrm{Au}$ and thiols has also been confirmed by $\mathrm{X}$-ray photoelectron spectroscopy with synchrotron radiation 
(SR-XPS) [47]. The relative amounts of $\mathrm{Au}$ and $\mathrm{S}$ atoms with different coordinations (i.e., bulk $\mathrm{Au}$ atoms, surface $\mathrm{Au}$ atoms binding thiol, $\mathrm{S}$ atoms chemisorbed on $\mathrm{Au}, \mathrm{S}$ atoms physisorbed and free thiolate groups) can be quantified by discriminating the corresponding contributions to $S 2 p$ and $\mathrm{Au} 4 \mathrm{f}$ signals. By evaluating the signal intensity ratios, Polzonetti et al. [47] concluded that about $10 \%$ of total gold atoms (bulk and surface) are covalently bonded to thiols. In addition, the presence of physisorbed thiols, probably constituting a second layer, has been observed, demonstrating that different interactions are possible at the metal-ligand interphase. Although HSAB theory is effective in qualitatively predicting metal-ligand interactions, it does not always agree with experimental results, as in the case of the PVP-metal system. XPS analysis of PVP-protected silver nanowires [48] revealed a shift to higher binding energy for $\mathrm{O}(1 \mathrm{~s})$ peak from the carboxyl oxygen $(\mathrm{C}=\mathrm{O})$ atom, whereas the $\mathrm{N}(1 \mathrm{~s})$ signal remains unaltered compared to pure PVP spectrum. This can suggest a preferential interaction of silver atoms with oxygen in disagreement with HSAB principles ( $\mathrm{N}$ being a softer base than $\mathrm{O}$ should present a stronger interaction with metals). Furthermore, monitoring the carbonyl region in diffuse reflectance infrared Fourier transformed (DRIFT) spectroscopy, a positive shift in the carbonyl stretching band has been detected for submicrometric PVP-Ag particles; whereas a negative shift has been observed for nanometric particles. According to the literature, these results can be explained by a possible PVP coordination to Ag submicrometric particles through the $\mathrm{N}$ atom of the heterocyclic ring. In the case of Ag nanoparticles, the interaction involves the $\mathrm{O}$ atom of the PVP amide group. This implies a size-dependence in the coordination of the PVP to the metal nanoparticles [48].

A more rigorous description of charge transfer should take into account the modification of the pristine ligand electronic structure induced by the metal. Indeed, according to the model proposed by Flores et al. [49], the chemical interaction between the metal and the ligand leads to the creation of an induced density of interface states (IDIS) in the ligand HOMO-LUMO gap. A key parameter is the charge neutrality level (CNL), which can be considered as a sort of Fermi level for the ligand at the interface. The misalignment between the Fermi level and the CNL governs the direction and the extent of the charge transfer. The electron charge will flow from metal to ligand or vice versa, depending on the sign and on the magnitude of the energy difference between the metal Fermi level and ligand charge-neutrality level. In other terms, when $\mathrm{CNL}>\mathrm{E}_{\mathrm{f}}$, the electron charge transfer will occur from the ligand shell to the metal surface; while when $\mathrm{CNL}<\mathrm{E}_{\mathrm{f}}$ the electrons will flow from the metal to the ligand layer. Experimental evidences for the charge transfer have been obtained using different characterization techniques. In addition to LSPR Spectroscopy, XPS and Infrared Spectroscopy, mentioned above, the electronic structure at the interface has been probed using Surface Enhanced Raman Spectroscopy (SERS) [50], Scanning tunneling spectroscopy (STS) [51] and electrochemical techniques [52]. However, the current approach is based on ex situ characterization. Therefore, few information are available about the electronic structure of the metal-ligand interphase and its evolution under reaction conditions [53]. A fruitful support can derive from theoretical studies. The most common approach to the description of metal-ligand interphase is based on Density Functional Theory (DFT). The main challenge in predicting the electronic structure at the interphase from first principles consists in the selection of an approximate exchange-correlation density functional, able to accurately describe both sides of the interface [54]. Indeed, the presence of unexpected collective effects (charge transfer, polarization, interface-induced states, orbital hybridization) requires the introduction of hybrid functional, taking into account the contribution of the interface dipole. In the case of large molecules (e.g., polymers), a correct evaluation of the interaction energy should consider also the components assigned to the torsion, the deformation of bond angles and lengths [55].

\subsubsection{Activity and Selectivity Enhancement Induced by Charge Transfer}

Electronic changes at the metal-ligand interphase unavoidably affect the catalytic behaviour of capped nanoparticles, introducing either a poisoning or promoting effect. The border between these effects is very labile and it is strictly related to the nature and the intensity of the metal-ligand interactions. Indeed, the kinetics of the catalytic cycle depends strongly on the competition between 
reactant and ligand molecules to adsorb on the active sites. A strong interaction between metal surface and pre-existing ligand molecules will prevent a successive adsorption and activation of the reactant during the reaction, thus producing a poisoning effect. This effect is more evident comparing the catalytic activity of metal NPs prepared with different ligands. For example, it has been demonstrated [56] that the activity of iridium nanoparticles synthesized with three different ligands (oleic acid/oleylamine- $\mathrm{OA}$, tetraoctylammonium bromide- $\mathrm{TOAB}$, and tetraoctylphosphonium bromide-TOPB) in 1-decene hydrogenation (TOPB $>$ TOAB $>$ OA) is inversely proportional to the ligand-metal binding strength (Ir-O > Ir-N > Ir-P).

On the other hand, the altered electron density originated by charge transfer process at the metal ligand interphase can promote the activation of the adsorbed reactant, thus enhancing the catalyst activity. A similar effect has been revealed by Tsukuda et al. for PVP-protected Au nanoparticles [57]. The electron donation by PVP molecules adsorbed on gold surface increased the electron density on $\mathrm{Au}$ core, inducing the formation of $\mathrm{Au}^{\delta-}$ surface states, able to activate dioxygen generating superoxo- or peroxo-like species (Figure 4). These species are probably responsible for the enhanced activity in p-hydroxybenzylalcohol oxidation observed in the case of PVP protected Au NPs compared to their naked counterparts.

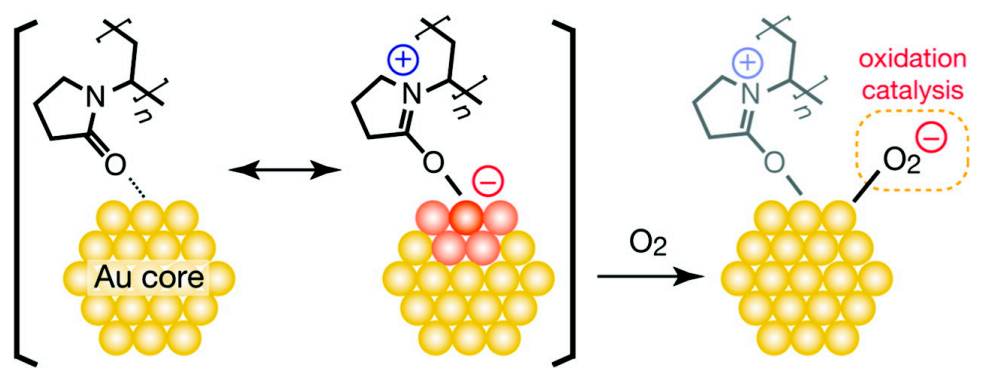

Figure 4. Dioxygen activation by PVP-induced charge transfer. Reproduced with permission from ref. [57]. Copyright2009, American Chemical Society.

Electro-donation from ligands to metal does not always lead to a beneficial effect. Recently, Michaelis et al. [58] investigated the possibility to tailor the catalytic performances of bimetallic RuCo NPs, by properly tuning the electronic properties and the donor ability of the protecting polymer. The introduction of electron-donating substituents on polystyrene chains leads to a reduced electron density and a weaker interaction between metal nanoparticle surface and arene $\pi$-electrons, which allows polystyrene to dissociate from metal surface. Consequently, the metal surface accessibility and the catalyst activity in nitroarenes reduction are enhanced. Conversely, the introduction of electron-withdrawing substituent transforms polystyrene into an electron-rich system that strongly interacts with the metal surface and further acts as a poisoner [58].

Electron donation from electron-rich capping agents to the metal surface can be also exploited to control the selectivity of a reaction, by favouring the adsorption of electron deficient substrates. This interfacial electronic effect has been proven by Zheng et al. for the selective partial hydrogenation of nitroaromatic compounds [59]. In this case, the modification of Pt catalysts with ethylenediamine (an electron-rich species) leads to an enhanced selectivity to the hydroxylamine, the product of the partial hydrogenation of the nitro group. Indeed, electron-rich Pt surface interacts preferentially with nitrobenzene (electron-deficient species), which is partially reduced to the corresponding hydroxylamine. The latter is an electron-rich molecule and therefore it rapidly desorbs without undergoing further hydrogenation to amine.

In other cases the competitive effect between metal-ligand and metal-substrate interactions is on the basis of a modified selectivity of a reaction. Shevchenko and co-workers [60] studied the effect of the capping agent on the selectivity in the hydrogenation reaction of alkynes to alkenes. The main limitation of this reaction is the very low selectivity to alkenes, due to the fast over-hydrogenation of 
the as-obtained alkenes to alkanes. Using trioctylphosphyne oxide (TOPO) as capping agent of Pt and bimetallic CoPt nanoparticles, a high selectivity to alkenes has been achieved (selectivity to 4-octene greater than $90 \%$, in the case of 4-octyne hydrogenation). Based on DFT calculations, it is possible to correlate the higher alkenes' selectivity to a delicate balance between the adsorption energy of the ligand and the one of the possible substrate [60]. In particular, the adsorption energy of the ligand is lower than the one of the alkyne, therefore it does not significantly reduce the activity in the alkynes semi-hydrogenation to alkenes. Comparing the adsorption energy of TOPO ligand and that of the alkene, we can assume a stronger interaction between the metal and the ligand than between the metal and the alkene.

Consequently, the ligand acts as a poisoner for the transformation of the alkene, which cannot undergo further hydrogenation to alkane. A similar effect has been evidenced by Kaneda et al. [61] in the case of dimethylsulfoxide (DMSO)-protected Pd nanoparticles.

These competitive effects and preferential interactions can concern also different functionalities in the same molecule, as in the case of 1-epoxy-3-butene hydrogenation [62]. Unsaturated epoxides contain both epoxide ring and a $\mathrm{C}=\mathrm{C}$ double bond. Therefore, the hydrogenation of the unsaturated epoxides proceeds with a complex reaction pathway and a large product distribution. Recently, Medlin and co-workers [63] reported on the selective hydrogenation of 1-epoxy-3-butene to 1-epoxy-3-butane on palladium nanoparticles protected by a self-assembled monolayer (SAM) of alkanethiols.

In many metal surfaces, because of the strong affinity of the sulfur group ("head group"), alkanethiols adsorb strongly with the head group onto the metal surface, while the hydrocarbon "tail" is oriented at a well-defined angle with respect to the surface. Therefore, the enhanced selectivity obtained in presence of alkanethiol SAMs could be ascribed either to geometric effect that derives from the ordered morphology of the organic layer or to electronic effect induced by the Pd-S interaction. Experiments with SAMs, composed by hydroxy-terminated C3 and C6 alkanethiols and thioglycerol, revealed no influence of the tail identity on the selectivity [62]. Therefore, the Pd-S is responsible for the unexpected selectivity. Due to electron-withdrawing effects deriving from the strong Pd-S binding, adsorbate interacts more weakly with metal, preferring bond-making reactions to bond-breaking reactions, the latter requiring stronger interactions. Temperature programmed desorption (TPD) experiments, supported by DFT calculations, demonstrated that oxygen moieties are more affected by the presence of Pd-S compared to olefin group. The reactant molecule tends therefore to interact with the metal through the $\mathrm{C}=\mathrm{C}$ double bond.

Besides reactant and product molecules, intermediate and activated complex can also interact differently with the metal surface according to the presence or absence of the capping agent. $\mathrm{Xu}$ et al. reported the higher activity of PVP-protected Au NPs in $p$-chloronitrobenzene hydrogenation compared to the unprotected ones [64]. This higher activity was explained by a higher entropy of activation of the substrate due to a higher mobility of the activated complex. The mobility is facilitated by a weakened interaction of the substrate with the metal in the case of protected nanoparticles.

\subsubsection{Shielding Effect and Selective Blocking}

The presence of the capping agent layer may block access to reactants and consequently have a detrimental effect on the activity. Recently, a drop in the activity due to the PVA shielding effect has been reported for supported gold catalyst in glycerol oxidation [65].

Instead, the removal of the stabilizing agent through oxidative or thermal treatment usually produces an increase in particle size and a shape modification, thus negatively affecting catalyst activity and stability. These drawbacks have been overcome by Hutching' group [27], who proposed an innovative procedure based on solvent washing. This approach requires milder operative conditions thus allowing to limit the alteration of particle size and morphology compared to traditional method.

By using a similar procedure and by monitoring the protecting agent removal by IR spectroscopy, Villa et al. [65] demonstrated that the relative amount of residual protecting agent represents a key 
factor in determining the catalytic performances of $\mathrm{Au} / \mathrm{TiO}_{2}$ catalysts. Indeed, washing with water at $298 \mathrm{~K}$ yields just a partial removal of the capping agent (PVA), as confirmed by IR spectra and HRTEM images (Figure 5).

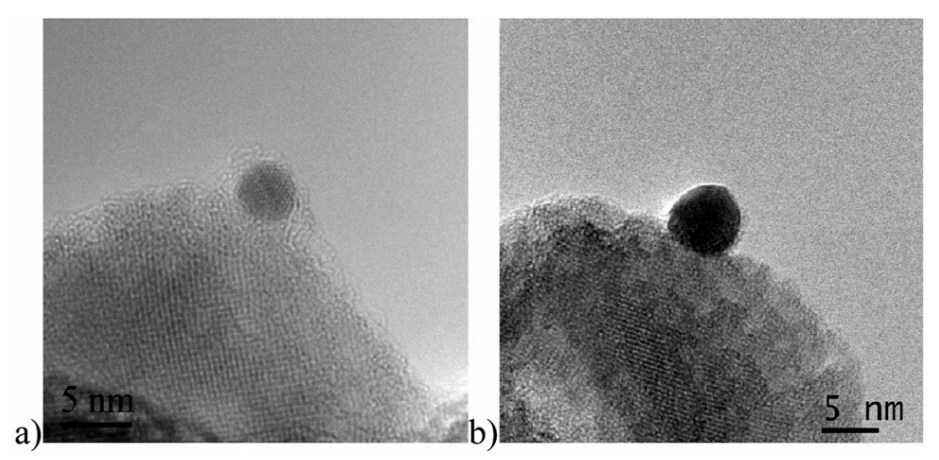

Figure 5. HRTEM images of Au NPs: (a) protected and (b) partially covered by PVA. Reproduced from ref. [65] with permission of The Royal Society of Chemistry.

The resulting catalyst was more active than the one washed at $333 \mathrm{~K}$, in which PVA was completely removed (Table 1). This evidence suggested that dosing the amount of capping agent could be a crucial parameter for obtaining catalyst with enhanced activity.

Furthermore, in some cases the ligand-induced shielding effect can be exploited for directing the selectivity of structure sensitive reactions.

Table 1. Effect of the capping agent amount on the glycerol oxidation (Data from ref. [65] with permission of The Royal Society of Chemistry).

\begin{tabular}{|c|c|c|c|c|c|c|c|}
\hline & \multirow{2}{*}{ Catalyst $^{\mathrm{a}}$} & \multicolumn{6}{|c|}{ Selectivity ${ }^{c}(\%)$} \\
\hline & & Activity $\mathrm{mol}^{\mathrm{b}}(\mathrm{Au} \mathrm{mol})^{-1} \cdot \mathrm{h}^{-1}$ & Glyc & Gly & Tar & $\mathbf{F}$ & Lac \\
\hline 1 & AuPVA (1:1) & 236 & 81 & 3 & 5 & 2 & 9 \\
\hline 2 & AuPVA (1:0.5) & 282 & 78 & 5 & 4 & 3 & 10 \\
\hline 3 & AuPVA (1:0.25) & 356 & 75 & 4 & 5 & 5 & 11 \\
\hline 4 & AuPVA (1:0.125) & 434 & 70 & 12 & 2 & 9 & 7 \\
\hline 5 & AuPVA (1:1) washed at $298 \mathrm{~K}$ & 355 & 77 & 6 & 3 & 4 & 10 \\
\hline 6 & AuPVA (1:1) washed at $333 \mathrm{~K}$ & 138 & 68 & 14 & 3 & 7 & 8 \\
\hline 7 & AuDP & 390 & 69 & 12 & 2 & 9 & 8 \\
\hline 8 & AuDP + PVA $(1: 1)$ & 255 & 76 & 5 & $\overline{7}$ & 3 & 9 \\
\hline 9 & AuDP + PVA (1:0.125) & 401 & 70 & 10 & 5 & 7 & 8 \\
\hline
\end{tabular}

From a catalytic point of view, structure sensitive reactions can proceed through different pathways. These routes are directly associated with specific active sites (crystal plane, edge, corner, see Figure 6) on the metal nanoparticle, leading to a different rate and/or product distribution.

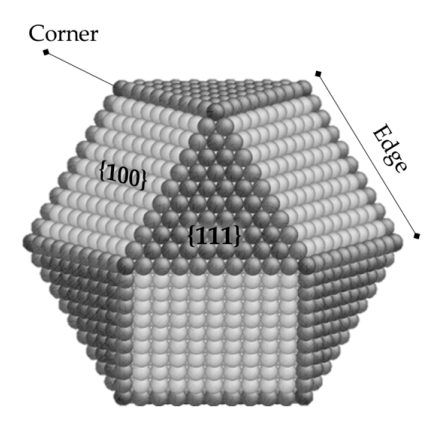

Figure 6. Schematic representation of typical active sites in an cuboctahedral metal nanoparticle. 
Concomitantly with the metal nanoparticle growth, lattice rearrangements generally occur in order to minimize the surface energy. Consequently, the thermodynamic equilibrium shape (truncated octahedron and cuboctahedron being the most common) is usually characterized by the exposition of lowest-index $\{111\},\{100\}$, and $\{110\}$ crystal planes [66].

As mentioned before, the strong interaction between ligand molecules and metal surface often reduces the catalytic activity due to blocking site effects. However, depending on the match between the molecular size and geometry of the ligand, and the metal surface lattice constant and symmetry, often preferential ligand binding can occur on specific sites of the metal NP. Therefore, by selecting a proper ligand, which strongly adsorbs only on specific active sites (selective blocking), it is possible to suppress undesirable processes without affecting the overall activity of the catalyst. By combining Attenuated Total Reflection Infrared spectroscopy (ATR-FTIR), thermogravimetric desorption and DTF calculations, Baiker et al. [67] were able to selective blocking oxidation and hydrogenation sites on supported Au nanoparticles, choosing the appropriate ligand. $N$-octadecanetiol was found to act as poisoner of Au catalyst in the benzyl alcohol oxidation; whereas mercaptoacetic acid is a stronger poisoning agent in the hydrogenation reaction of ketopantolactone. DFT calculations indicated that $n$-octadecanetiol preferentially adsorbs on extended Au terraces, active sites for oxidation reactions. Mercaptoacetic acid tends to adsorb on crystal edges and corners, suggesting that hydrogenation occurs specifically on defected sites.

More recently, Campisi et al. [68] ascribed the improved selectivity in benzyl alcohol oxidation to the presence of PVA on Pd NPs. Investigating the surface site accessibility through DRIFTS-monitored $\mathrm{CO}$ adsorption, they attributed the peculiar catalytic behaviour to the preferential blocking of $\operatorname{Pd}(111)$ facets, which have been recognized to promote the decarbonylation process [69] by residual PVA (Figure 7). Indeed, the removal of PVA by mild calcination completely restored the signal at $1980 \mathrm{~cm}^{-1}$ in DRIFT spectra, ascribed to the $\mu_{2}$ bridge-bonded CO on Pd(100), which was shifted to $1960 \mathrm{~cm}^{-1}$ in PVA-protected Pd NPs. Instead, the signal at $1925 \mathrm{~cm}^{-1}$, ascribed to the perturbation of CO coordination on (111) plane, resisted calcination, thus indicating a stronger interaction of PVA with $\operatorname{Pd}(111)$ facets.
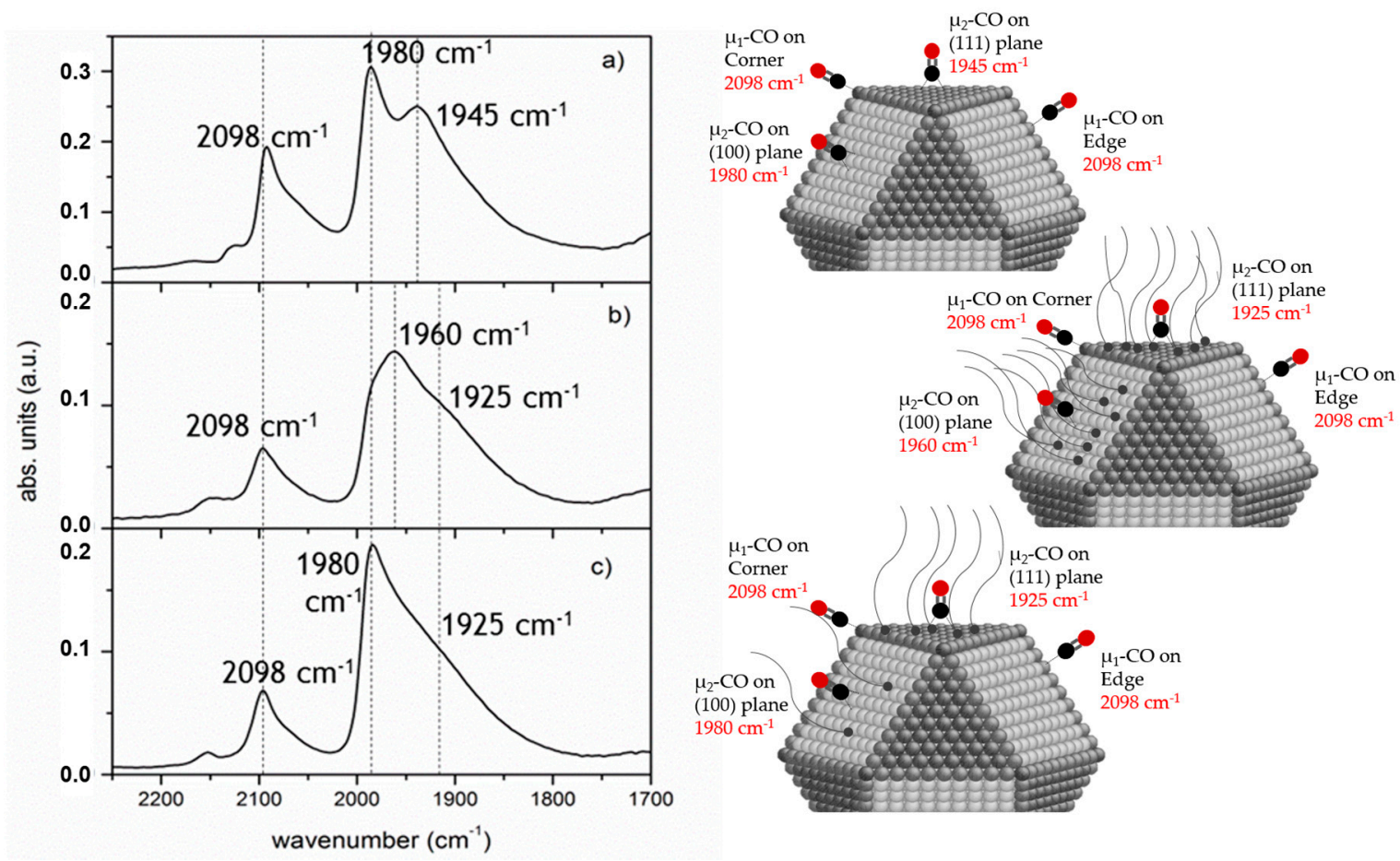

Figure 7. DRIFT spectra of adsorbed CO on (a) naked and protected Pd NPs (b) before and (c) after calcination. Reproduced with permission from ref. [68]. Copyright2016, American Chemical Society. 


\subsection{The Orientation of Molecules and the Morphology of Metal-Ligand Interphase}

From a catalytic point of view, the morphology of the capping agent shell plays an essential role, since it determines the steric hindrance provided by the shell itself. Indeed, according to their spatial arrangement, ligand molecules surrounding the metal nanoparticle might limit the mobility of reactants and force them to rearrange the adsorption geometry close to the active site.

Moreover, the fashion of ligand molecule packing and ordering on the metal surface affects also the wetting behaviour and then the solubility of the metal nanoparticles [70], as described into details in the next section.

Despite the need to control and optimize the shell morphology, predicting and studying the orientation of molecules on metal surface is still a challenging field. As a general assumption, the balance between the intermolecular interactions (cohesion energy) and the metal-molecule binding forces (adhesion energy) governs the molecular orientation at metal-ligand interphase.

The intermolecular interactions depend on the chemical composition of the ligand shell and usually include weak van der Waals forces (e.g., London dispersion force), electrostatic forces, directional hydrogen bonding, $\pi-\pi$ interactions between adjacent molecules.

The metal-molecule interactions result from the electronic coupling between molecular orbitals of the ligand and the electronic surface states of the metal NP, whose nature and strength have been treated in the previous section.

A standing-up orientation is preferred when intermolecular interactions prevail on metal-molecule interactions. When metal-molecule interactions dominate, a flat-lying arrangement is favoured, to maximize the orbital overlapping and the electron coupling (Figure 8). The final geometry will be an intermediate between these two extremes, depending on the relative weight of each contribution.

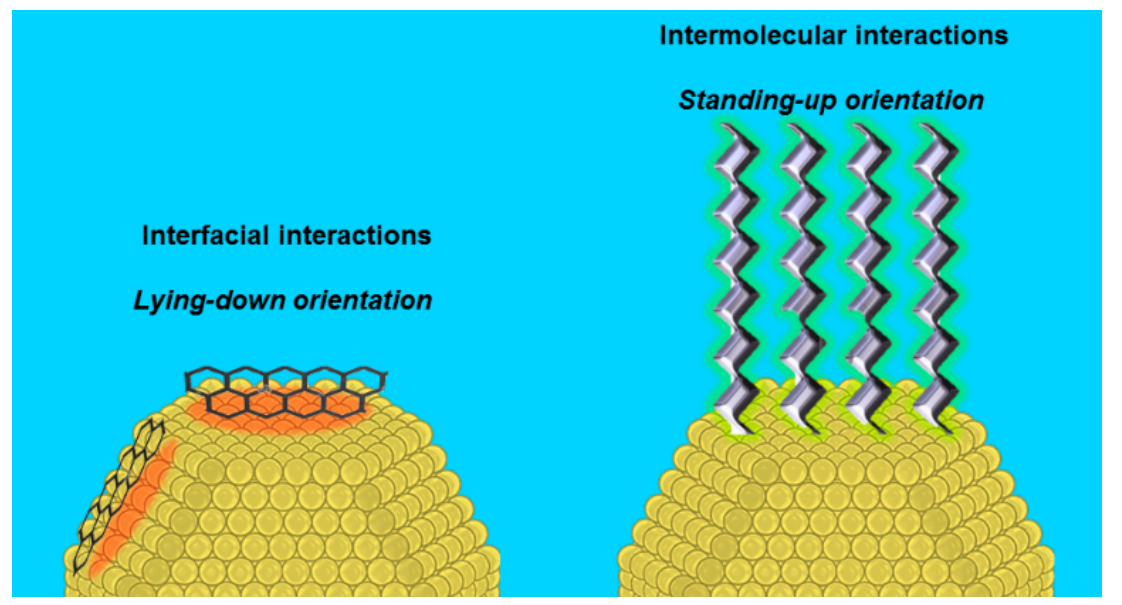

Figure 8. The role of interactions in determining the orientation of ligand molecules.

Besides the balance between intermolecular and metal-molecule interactions, the morphology of the ligand shell is a function of chain length, surface coverage degree and surface curvature of the metal nanoparticle.

Direct experimental determination of molecular orientation on metal nanoparticle surface is nontrivial and time-consuming, since it often requires the combination of several structural measurements using different characterization techniques.

Scanning Tunnelling Microscopy (STM) based on the quantum tunnelling phenomena, is a powerful tool to determine the surface topography and qualitatively visualize the ligand orientation and assembling. Since the pioneer works of Vogel [71] and Wang [72], reporting the STM-investigation of the ligand shell morphology in surfactant-protected Pd NPs and in PVP-protected Pt NPs, respectively, STM imaging techniques have been widely employed to obtain information at 
molecular scale about the ligand organization. Recently, Majima et al. summarized progresses in the STM-based characterization of ligand capped nanoparticles [73]. In this context, it is worthwhile to mention the contribution of Stellacci et al., who thanks to high-resolution STM reported the peculiar formation of ribbon-like domains of alternating composition in the mixed-ligand (e.g., octanethiol-mercaptopropionic acid) shell on Au and Ag NPs [74]. Furthermore, the same author unravelled the role of ligand layer morphology in determining the metal MP surface properties, such as the wettability [70].

Despite the capability of STM to provide single-particle data at atomic resolution, just the top molecular layer is accessible and this limit the application of this technique for probing the local structure in the proximity of the active sites.

The quantitative determination of molecular organization in nanostructured systems can be obtained by angular dependent near-edge X-ray absorption fine structure (NEXAFS) spectroscopy. NEXAFS exploits the interaction between the polarized synchrotron radiation and the molecular antibonding orbitals with strong directional character, in order to determine the orientation of the molecular orbitals of an adsorbed molecule in respect to the surface [75] (for a more complete treatment of NEXAFS the reader could refer to [76]). As an example, by using angular dependent NEXAFS at the C K-edge, Polzonetti et al. demonstrated that 4-trimethylsilylethynyl-1-acetylthiobenzene (SEB) arrange according to a flat-lying orientation on the Au NP surface in systems with a thin molecular shell [47].

Parker et al. [77] recently proposed an elegant study on the conformation of adsorbed alkanethiol ligand at palladium NP surface, based on the combination of experimental details from Inelastic neutron scattering spectroscopy and DFT calculations. INS spectroscopy is an ideal tool for the investigation of ligand shell structure, since it provides information solely on the organic component.

\subsubsection{Steric Effects and Surface Crowding}

Steric effects and surface crowding effects include all superficial phenomena directly related to the packing density, the morphology, the order degree and the thickness of the ligand shell. Two main mechanisms can be identified: the control of the reactant adsorption mode and the active site isolation. The former is essentially determined by intermolecular interactions between ligands and reactants; while the latter is ruled by geometrical factors. In most of the cases, the steric effect is a combination of both mechanisms.

A recent example is the selective hydrogenation of cynnamaldehyde reported by $\mathrm{Fu}$ and coworkers [78]. Cynnamaldehyde is a typical $\alpha, \beta$-unsaturated aldehyde and, when it undergoes hydrogenation, the thermodynamic more stable product is the corresponding saturated aldehyde. However, when amine-capped $\mathrm{PtCo}$ nanoparticles are used as catalyst for this reaction, an unexpected chemoselectivity to cynnamyl alcohol can be observed. This unpredictable result can be attributed to van der Waals interactions between ligand (e.g., octylamine) and reactant molecules, which promote the eclipsed conformation over the staggered one and inhibit the flat mode adsorption on metal surface, thus preventing the further hydrogenation of $\mathrm{C}=\mathrm{C}$ bond. The steric hindering of flat adsorption mode could explain the chemoselective reduction of 4-nitrostyrene to 4-aminostyrene with SAM-protected Pt NP catalyst [79].

The creation of a confined space with high local reactant concentration and geometrical constraints directing the adsorption geometry is responsible of the high activity and selectivity of PtRu NPs inside multiwalled carbon nanotubes (MWCNTs) in the hydrogenation of cynnamaldehyde [80]. Analogously, diphenyl sulphide ligands on $\mathrm{Pd} / \mathrm{TiO}_{2}$ surface generate an appropriate ensemble which accommodates alkynes, but prevents the adsorption of alkenes, thus promoting the selective hydrogenation of acetylene to ethylene [81]. Residual PVA on $\mathrm{TiO}_{2}$-supported $\mathrm{Au}$ NPs results in a porous-like structure in which the $\mathrm{OH}$ groups of PVA interact with the analogous groups of glycerol [65]. The adsorption of the reactant is therefore directed on the active site leading to a modification of the selectivity of in glycerol oxidation. In particular, in the presence of PVA glycerol molecules preferentially adsorbs 
with standing-up orientation (Figure 9). This adsorption mode favours the selective oxidation of primary alcohol functions of glycerol, resulting in a high selectivity to glyceric acid and tartronic acid (see Table 1, entries 1-5). Conversely, the $\mathrm{C}-\mathrm{C}$ bond cleavage and the consequent $\mathrm{C} 2$ and $\mathrm{C} 1$ compound production (glycolic acid and formic acid, see Table 1) are promoted by a flying-down orientation, which is favoured in the case unprotected Au NPs [65].

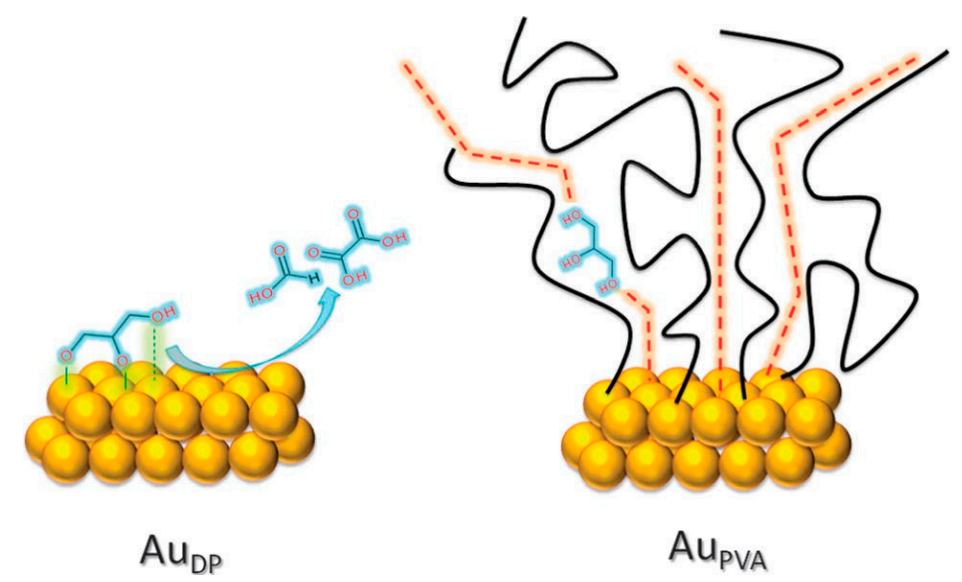

Figure 9. Model for glycerol adsorption on the surface of naked (left) and protected (right) gold NPs Reproduced from ref. [65] with permission of The Royal Society of Chemistry.

In some cases, the solvent can also play an important role by influencing the conformation of the ligand. Dodecylthiosulfate assumes alternatively outstretched or huddled conformations in nonpolar or polar protic solvents, respectively. It is thus possible to switch the selectivity of S-dodecylthiosulfate-capped Pd from allyl alcohol hydrogenation to allyl alcohol isomerization by properly selecting the solvent [82].

The active site isolation effect depends on the coverage density of capping agents and it consists in the dilution of contiguous active sites using a densely packed monolayer. This effect has been used for preventing the formation of undesired benzyl benzoate in the Au-catalysed selective oxidation of benzyl alcohol to benzaldehyde: benzaldehyde and benzyl alcohol are distanced by adsorbed capping agents and prevented to react together forming the ester (Figure 10) [83].
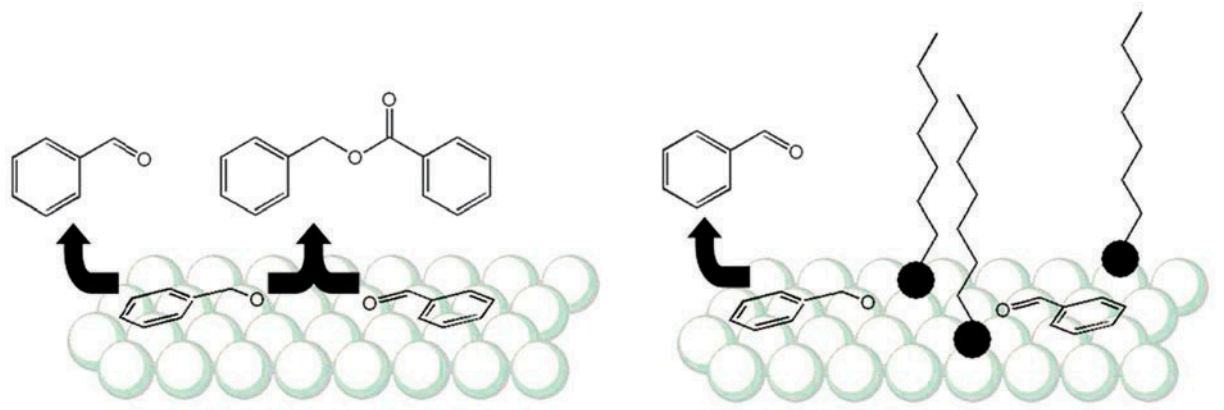

Figure 10. Active site isolation effect in benzyl alcohol oxidation. Reproduced from ref. [83] with permission of The Royal Society of Chemistry.

An elegant combination of site isolation and selective blocking (see Section 2.1.2) effects has been proposed by Medlin et al. [84] for the selective hydrogenation of furfural using alkanethiolate SAM-modified Pd catalysts (Figure 11). The selectivity to value-added compounds, i.e., furfuryl alcohol and methylfuran, increased expanding the packing density of the SAM due to limited access to the threefold terrace sites. Indeed, these sites are active in the undesired decarbonylation and ring hydrogenation reactions. 


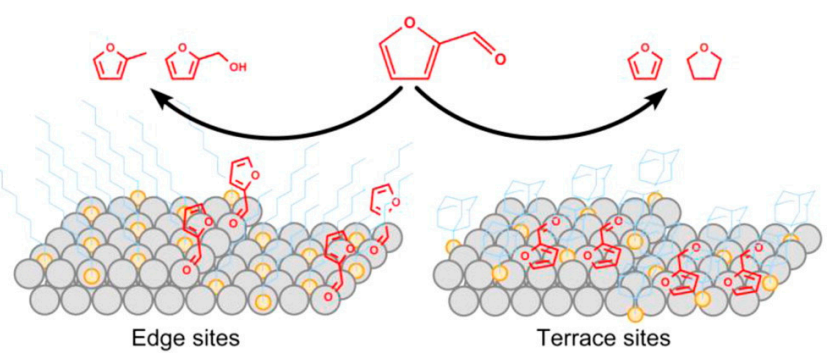

Figure 11. Site isolation and selective blocking effects for the selective hydrogenation of furfural Reproduced with permission from ref. [84]. Copyright2014, American Chemical Society.

\subsubsection{Molecular Recognition}

The concept of molecular recognition is based on the noncovalent interactions between reactants and ligands on the metal surface. It derives from metalloenzymes whose selectivity derives from the molecular recognition of reactants by periphery proteins surrounding the metallic cluster. Many attempts have been devoted to design heterogeneous catalysts mimicking the catalytic specificity of enzymes. Miki and co-workers reported the unprecedented catalytic performances of alkanethiol-SAM-capped Au nanoparticles in silane alcoholysis reactions [85]. The well-ordered 2D array of alkanethiol strongly interacts with the reactants molecules by hydrophobic interactions and encapsulates them, thus increasing the local concentration of reactant in the proximity of gold surface. The increase in the apparent concentration results in an enhanced reaction rate and consequently in a surprising activity (TOF up to $55,000 \mathrm{~h}^{-1}$ ). Differently, the complementarity between the molecular dimensions of reactant and the alkanethiol spacing controls the selectivity of the process.

The mechanism of the molecular recognition has been extensively investigated by Medlin and co-workers [86]. By exploiting noncovalent interactions and matching degree between the molecular structures of both reactants and ligands, they were able to rationally tune the selectivity of cynnamaldehyde hydrogenation towards the maximization of cinnamyl alcohol production. In order to reproduce a controlled reaction environment similar to the one of metalloenzyme, $\mathrm{Pt} / \mathrm{Al}_{2} \mathrm{O}_{3}$ surface was covered with different organic thiol SAMs and the catalysts were tested in cynnamaldehyde hydrogenation. In all cases, a higher selectivity to cynnamyl alcohol was obtained compared to naked particles. Indeed, due to the presence of thiol molecules, the cynnamaldehyde has to adopt the "upright" adsorption geometry (confirmed via polarization modulation-reflection absorption infrared spectroscopy), which favours the hydrogenation of carbonyl moieties. In the case of naked particles, the flat adsorption mode is favoured leading to the complete hydrogenation. The highest selectivity to cinnamyl alcohol was obtained using 3-phenyl-1-propanethiol SAM [87]. This result can be rationalized considering the presence of a phenyl group resulting in additional noncovalent aromatic $\pi-\pi$ stacking with the phenyl substituent of cynnamaldehyde, and the match between spacer length in the modifier (three-methylene spacer between the $S$ atom and the phenyl ring) and the structure of cynnamaldehyde (Figure 12).

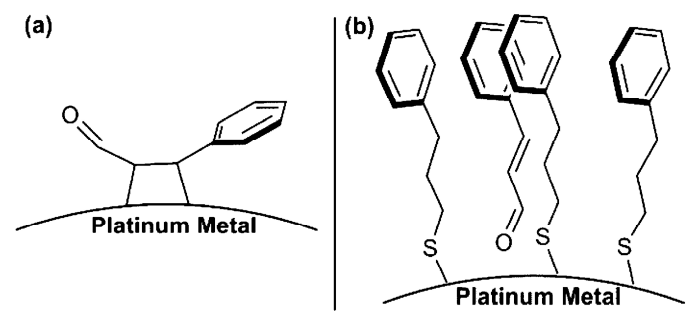

Figure 12. Adsorption model for Cinnamaldehyde on the catalyst surface: (a) flat adsorption mode through the $\mathrm{C}=\mathrm{C}$ double bond onto uncoated Pt surface; (b) upright molecular orientation in the presence of 3-Phenyl-1-propanethiol SAMs. Reproduced with permission from ref. [87]. Copyright 2014, American Chemical Society. 


\subsubsection{Stereo-Directing Interaction between Ligands and Reactants}

Enantioselective synthesis characterized by a high enantiomeric excess of the target stereoisomer is of fundamental importance for pharmaceutical and agrochemical industries, where the production of racemic mixtures is not permitted because of legislative restrictions. Therefore, since 1980s, significant efforts were focused on the design of asymmetric heterogeneous catalysts. A detailed discussion of this topic can be found in a recent literature [88] and it is beyond the scope of this review article.

The use of chiral ligands is a suitable strategy for conferring enantioselectivity to both homogenous and heterogeneous catalysts. With heterogeneous catalysts, tartaric acid and cinchonidine derivatives seem to be the most used ligands in enantioselective hydrogenation. Tartaric acid has been used as modifier of Ni-Raney catalysts for the hydrogenation of $\beta$-keto esters [89]. Chinchonidine and its derivatives are effective modifier when Pd and Pt nanoparticles are used as catalysts in the enantioselective hydrogenation of unsaturated functional groups, namely activated ketones and functionalized olefins [90]. From a mechanistic point of view, the origin of the high enantioselectivity in these reactions can be ascribed to the interactions between the prochiral substrate and the anchored chiral modifier, which directs the adsorption geometry. DTF calculations were used for studying the co-adsorption of cinchonidine and ketones on Pt surface [91]. The alkaloid forms a three-dimensional space (chiral pocket) where the reaction preferentially occurs due to a close interaction between ketone and the nitrogen atom of alkaloid. Enantioselectivity is a highly desired goal in main reactions. Asymmetric xylofuranoside diphosphite was used as stabilizer of palladium nanoparticles for the enantioselective allylic alkylation reaction of rac-3-acetoxy-1,3-diphenyl-1-propene with dimethyl malonate [92]. BINAP, 2,2'-bis(diphenylphosphino)-1,1'-binaphthyl), an organophosphorus chiral ligand, has been recently used by Kobayashi and co-workers [93] as ligand for the immobilization of Rh/Ag NPs. The polymer-incarcerated NPs display a good enantioselectivity in the asymmetric 1,4 -addition reactions of arylboronic acids to $\alpha, \beta$-unsaturated carbonyl compounds.

Despite the enhanced enantioselectivity, the use of large chiral ligand in many cases has a detrimental effect on the activity due to steric hindrance. To solve this problem, Somorjai, Toste, and co-workers [94] developed a heterogeneous catalyst with gold clusters encapsulated in chiral SAMs and then immobilized on mesoporous silica. The catalyst was tested in olefin cyclopropanation reactions and showed up to $50 \%$ enantioselectivity with high diastereoselectivity, which can be attributed to hydrogen bonding network orientating the reactant molecules inside the chiral SAMs, as confirmed by spectroscopic evidences. SAMs of cinchonidine-derivatized thiols were used also by Zaera et al. as protecting agent of Pt NPs for the hydrogenation reaction of $\alpha$-keto esters [95].

\subsection{Modelling the Kinetics and the Diffusion Process in Capped Nanoparticles}

In heterogeneous catalysis, reactants have to diffuse from the bulk of the solution toward the metal nanoparticle surface, to finally be adsorbed and react. Consequently, the total reaction rate is assumed to be the sum of the surface reaction rate $\left(r_{R}\right)$ and the diffusion rate $\left(r_{D}\right)$. The latter can be evaluated by the Debye-Smoluchowski model (Equation (1)), which describes the rate of a species $i$ diffusing under the effect of the chemical potential gradient from a bulk solution (at constant concentration $C_{i}^{0}$ ) toward a fixed target [96].

$$
r_{D}=4 \pi C_{i}^{0}\left[\int_{R}^{\infty} \frac{\exp \left(\Delta G_{s o l}(r) / k_{B} T\right)}{D(r) r^{2}} d r\right]^{-1}
$$

In the case of capped metal nanoparticles, the reaction rate can be splitted into two different contributions. The first one is the effective diffusion from the bulk solution to the ligand-solution interface. The second one is the diffusion through the metal-ligand interphase in order to reach the metal nanoparticle surface.

The effective diffusion is essentially connected to the diffusion coefficient $D_{0}$ in the solution (Fick's law) and is usually negligible compared to the diffusion rate across the ligand shell (Figure 13). 
Actually, the kinetics of this process is controlled by two key parameters: the diffusion coefficient of the reactants through the metal-ligand interphase $\left(D_{L}\right)$ and the thermodynamic free energy of solvation $\Delta G_{s o l}(r)$. The latter is the result of ligand-solute and solvent-solute interactions.

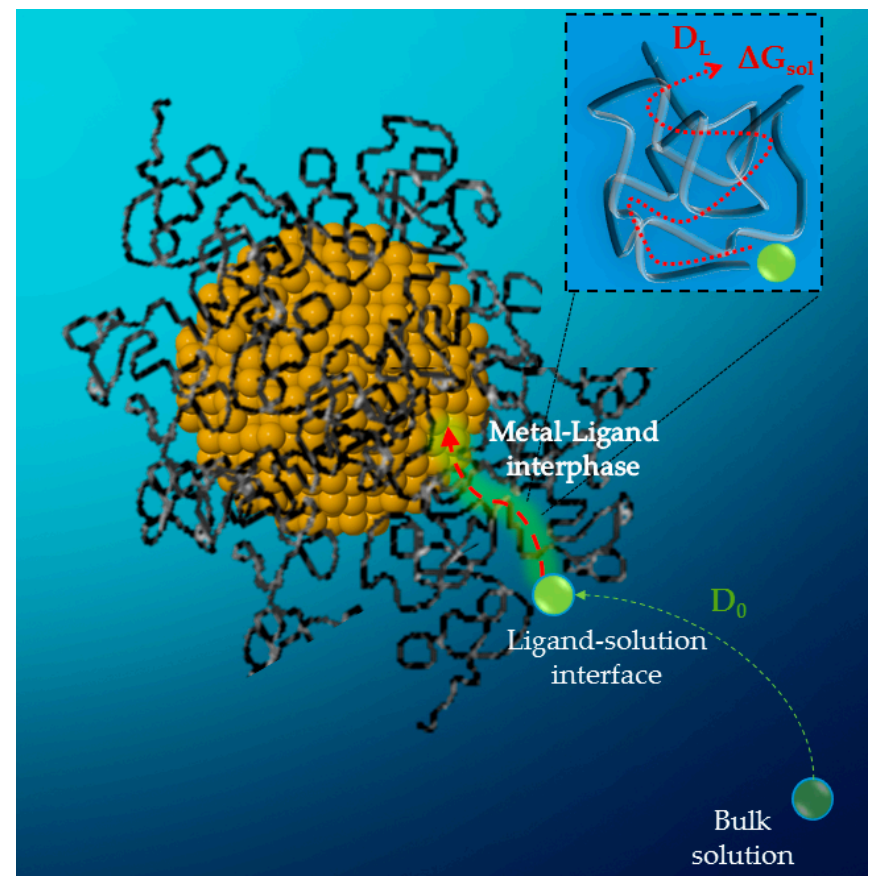

Figure 13. The diffusion process outside and inside the metal-ligand interphase.

Estimating the diffusion coefficient is relatively complicate in the case of polymer ligands. Indeed, the diffusion process in polymer matrix is a complex phenomenon which is affected by several factors, such as the polymer network, the diffusion structure, the solvent, the hydrodynamic interactions in the system and the temperature [97].

Various techniques have been employed to measure the diffusion coefficients, namely gravimetry, membrane permeation, fluorescence, radioactive labelling, dynamic light scattering and pulsed gradient nuclear magnetic resonance (NMR) spectroscopy. The interpretation of experimental data can be carried out according to several models that can be ascribed to three main theories.

In the diffusion models based on obstruction effects, polymer chains, because of their smaller self-diffusion coefficient, are considered as motionless in respect to the diffusing species (solvents and/or solutes) and appear as static and impenetrable sticks. A certain molecule can diffuse through the polymer shell only if its hydrodynamic volume is small enough to pass through the polymer chains [97].

The hydrodynamic theories derive from the Stokes-Einstein equation for solute diffusivity [97]. The solute is described as a hard sphere moving in a continuum and slowing down due to the hydrodynamic (solute-polymer, solute-solvent and polymer-solvent) interactions.

In the free volume theory, the spatial distribution of solvent, solute and polymer, leads to the formation of void spaces (that is volume not occupied by the matter), which are fundamental in determining the diffusion rate.

In many cases, the diffusional process cannot be explained just invoking these models, but a combination of all of them is required. Recently, the development of nanoreactors based on metal nanoparticles embedded in a stimuli-responsive polymer matrix, has represented a further incentive to rationalize the diffusion processes in protected metal nanoparticles [98].

$\mathrm{Lu}$ and co-workers [99] used a typical thermoresponsive poly( $N$-isopropylacrylamide) to obtain a core-shell system (Au-PNIPA yolk-shell particles). The polymer shell undergoes a phase transition 
from a hydrophilic to a hydrophobic phase above $308 \mathrm{~K}$. This transition can be exploited in competitive reactions, in the case of reactants with different hydrophilic character. For instance, when 4-nitrophenol (4-NP) and nitrobenzene (NB) are reduced with $\mathrm{NaBH}_{4}$ in aqueous solution, below $308 \mathrm{~K}$ the main product is 4-aminophenol deriving from reduction of 4-NP. Above $308 \mathrm{~K}$, the hydrophobic NB that has a higher affinity with the shell in the contracted state, is preferentially reduced [99].

The hydrophobic modification of metal surfaces can also result in an increase of the activity, due to the higher accumulation of hydrophobic reactants, as demonstrated by Zheng et al., who in situ generated a trans-polyacetylene layer on the surface of various Pd nanostructures (carbon-supported NPs, nanosheets and nanocubes) by polymerization of acetylene. The resulting coated-nanostructures where surprisingly more active in the hydrogenation of styrene than their naked counterparts [100].

\section{Conclusions and Perspectives}

The design of metal nanocatalysts with optimized catalytic performance is an open challenge.

The selection of the proper capping agent is a crucial issue for the synthesis of metal nanoparticles with controlled size, shape and surface-site distribution. However, once metal nanoparticles have been immobilized on the support, the presence of capping agent is no more essential, it could rather have an adverse impact on the catalytic behaviour. Far to be an absolute truth, the last statement is susceptible to several exceptions. Indeed, an increasing number of experimental evidences appeared, validating the unpredicted beneficial role of the capping agent in catalysis. In this respect, the use of selected capping agents could represent a complementary strategy to the crystal size and shape control for attaining the goal of active and selective nanocatalysts.

Nevertheless, although significant efforts have been devoted to investigate the geometric and environmental changes induced by capping agent molecules on the properties and catalytic performances of metal NPs, some discrepancies remain in the literature.

The main gaps lie in:

- The difficulty to synthesize nanocrystals with controlled shape, size and defect distribution in a reproducible manner and independently from the capping agent.

- The challenge of isolating the pure effect of the capping agent from other factors (nanoparticle structure, support, etc.)

- The need to distinguish and to separately control the different contributions (electronic and geometric) on the capping agent behaviour.

- The complexity of real experimental conditions compared to models.

A multidisciplinary approach is needed to overcome these gaps, by combining a:

- A fine control of the synthesis

- A characterization, able to integrate several ex situ and in situ techniques for probing processes at metal-ligand interface under reaction conditions

- The development of a comprehensive theory for the interpretation

A similar approach will result in significant advances in the rational design of capping agents for nanocatalysts.

Conflicts of Interest: The authors declare no conflict of interest.

\section{References}

1. Schmid, G. Nanoparticles: From Theory to Application, 2nd ed.; Wiley-VCH: Weinheim, Germany, 2011; pp. 1-4.

2. Rao, C.N.R.; Müller, A.; Cheetham, A.K. The Chemistry of Nanomaterials: Synthesis, Properties and Applications, 1st ed.; Wiley-VCH: Weinheim, Germany, 2006; Volume 1, pp. 1-11. 
3. Daniel, M.C.; Astruc, D. Gold nanoparticles: Assembly, supramolecular chemistry, quantum-size-related properties, and applications toward biology, catalysis, and nanotechnology. Chem. Rev. 2004, 104, $293-346$. [CrossRef] [PubMed]

4. Schwarz, J.A.; Contescu, C.I.; Putyera, K. Dekker Encyclopedia of Nanoscience and Nanotechnology, 3rd ed.; CRC Press: New York, NY, USA, 2014; Volume 3, pp. 1813-1904.

5. Astruc, D. Nanoparticles and Catalysis; Wiley-VCH: Weinheim, Germany, 2008; Volume 1.

6. Roucoux, A.; Schulz, J.; Patin, H. Reduced transition metal colloids: A novel family of reusable catalysts? Chem. Rev. 2002, 102, 3757-3778. [CrossRef] [PubMed]

7. Tao, F.F. Metal Nanoparticles for Catalysis: Advances and Applications, 1st ed.; Royal Society of Chemistry: Cambridge, UK, 2014.

8. Stark, W.J.; Stoessel, P.R.; Wohlleben, W.; Hafner, A. Industrial applications of nanoparticles. Chem. Soc. Rev. 2015, 44, 5793-5805. [CrossRef] [PubMed]

9. Astruc, D.; Lu, F.; Aranzaes, J.R. Nanoparticles as recyclable catalysts: The frontier between homogeneous and heterogeneous catalysis. Angew. Chem. Int. Ed. 2005, 44, 7852-7872. [CrossRef] [PubMed]

10. Van Santen, R.A.; Neurock, M. Molecular Heterogeneous Catalysis: A Conceptual and Computational Approach, 1st ed.; Wiley-VCH: Weinheim, Germany, 2006; pp. 83-160.

11. Schauermann, S.; Nilius, N.; Shaikhutdinov, S.; Freund, H.J. Nanoparticles for heterogeneous catalysis: New mechanistic insights. Acc. Chem. Res. 2012, 46, 1673-1681. [CrossRef] [PubMed]

12. Schlögl, R. Heterogeneous catalysis. Angew. Chem. Int. Ed. 2015, 54, 3465-3520. [CrossRef] [PubMed]

13. Villa, A.; Dimitratos, N.; Chan-Thaw, C.E.; Hammond, C.; Veith, G.M.; Wang, D.; Manzoli, M.; Prati, L.; Hutchings, G.J. Characterisation of gold catalysts. Chem. Soc. Rev. 2016, 45, 4953-4994. [CrossRef] [PubMed]

14. Morsbach, E.; Spéder, J.; Arenz, M.; Brauns, E.; Lang, W.; Kunz, S.; Baumer, M. Stabilizing Catalytically Active Nanoparticles by Ligand Linking: Toward Three-Dimensional Networks with High Catalytic Surface Area. Langmuir 2014, 30, 5564-5573. [CrossRef] [PubMed]

15. Villa, A.; Schiavoni, M.; Prati, L. Material science for the support design: A powerful challenge for catalysis. Catal. Sci. Technol. 2012, 2, 673-682. [CrossRef]

16. Smith, D.K.; Korgel, B.A. The importance of the CTAB surfactant on the colloidal seed-mediated synthesis of gold nanorods. Langmuir 2008, 24, 644-649. [CrossRef] [PubMed]

17. Gavia, D.J.; Shon, Y.-S. Catalytic Properties of Unsupported Palladium Nanoparticle Surfaces Capped with Small Organic Ligands. ChemCatChem 2015, 7, 892-900. [CrossRef] [PubMed]

18. Baygazieva, E.K.; Yesmurzayeva, N.N.; Tatykhanova, G.S.; Mun, G.A.; Khutoryanskiy, V.V. Polymer Protected Gold Nanoparticles: Synthesis, Characterization and Application in Catalysis. Int. J. Biol. Chem. Sci. 2014, 14, $14-23$.

19. Crooks, R.M.; Zhao, M.; Sun, L.; Chechik, V.; Yeung, L.K. Dendrimer-encapsulated metal nanoparticles: Synthesis, characterization, and applications to catalysis. Acc. Chem. Res. 2001, 34, 181-190. [CrossRef] [PubMed]

20. Noël, S.; Léger, B.; Ponchel, A.; Philippot, K.; Denicourt-Nowicki, A.; Roucoux, A.; Monflier, E. Cyclodextrin-based systems for the stabilization of metallic (0) nanoparticles and their versatile applications in catalysis. Catal. Today 2014, 235, 20-32. [CrossRef]

21. Raveendran, P.; Fu, J.; Wallen, S.L. Completely "green" synthesis and stabilization of metal nanoparticles. J. Am. Chem. Soc. 2003, 125, 13940-13941. [CrossRef] [PubMed]

22. Neouze, M.-A.; Schubert, U. Surface Modification and Functionalization of Metal and Metal Oxide Nanoparticles by Organic Ligands. Monatshefte Chem. Chem. Mon. 2008, 139, 183-195. [CrossRef]

23. Prati, L.; Villa, A. Gold colloids: From quasi-homogeneous to heterogeneous catalytic systems. Acc. Chem. Res. 2014, 47, 855-863. [CrossRef] [PubMed]

24. Li, D.G.; Wang, C.; Tripkovic, D.; Sun, S.H.; Markovic, N.M.; Stamenkovic, V.R. Surfactant Removal for Colloidal Nanoparticles from Solution Synthesis: The Effect on Catalytic Performance. ACS Catal. 2012, 2, 1358-1362. [CrossRef]

25. Campisi, S.; Chan-Thaw, C.E.; Wang, D.; Villa, A.; Prati, L. Metal nanoparticles on carbon based supports: The effect of the protective agent removal. Catal. Today 2016, in press. [CrossRef]

26. Rioux, R.M.; Song, H.; Grass, M.; Habas, S.; Niesz, K.; Hoefelmeyer, J.D.; Yang, P.; Somorjai, G.A. Monodisperse Pt nanoparticles with well-defined surface structure: Synthesis, characterization, catalytic properties, and future prospects. Top. Catal. 2006, 39, 167-174. [CrossRef] 
27. Lopez-Sanchez, J.A.; Dimitratos, N.; Hammond, C.; Brett, G.L.; Kesavan, L.; White, S.; Miedziak, P.; Tiruvalam, R.; Jenkins, R.L.; Carley, A.F.; et al. Facile removal of stabilizer-ligands from supported gold nanoparticles. Nat. Chem. 2011, 3, 551-556. [CrossRef] [PubMed]

28. Aliaga, C.; Park, J.Y.; Yamada, Y.; Lee, H.S.; Tsung, C.K.; Yang, P.D.; Somorjai, G.A. Sum Frequency Generation and Catalytic Reaction Studies of the Removal of Organic Capping Agents from Pt Nanoparticles by UV-Ozone Treatment. J. Phys. Chem. C 2009, 113, 6150-6155. [CrossRef]

29. Niu, Z.; Li, Y. Removal and utilization of capping agents in nanocatalysis. Chem. Mater. 2013, $26,72-83$. [CrossRef]

30. Wu, B.; Zheng, N. Surface and interface control of noble metal nanocrystals for catalytic and electrocatalytic applications. Nanotoday 2013, 8, 168-197. [CrossRef]

31. Grubbs, R.B. Roles of polymer ligands in nanoparticle stabilization. Polym. Rev. 2007, 47, 197-215. [CrossRef]

32. Sonström, P.; Arndt, D.; Wang, X.; Zielasek, V.; Bäumer, M. Ligand Capping of Colloidally Synthesized Nanoparticles-A Way to Tune Metal-Support Interactions in Heterogeneous Gas-Phase Catalysis. Angew. Chem. Int. Ed. 2011, 50, 3888-3891. [CrossRef] [PubMed]

33. Boudart, M. Principles of Heterogeneous Catalysis. In Handbook of Heterogeneous Catalysis; Ertl, G., Knözinger, H., Weitkamp, J., Eds.; Wiley-VCH: Weinheim, Germany, 1997; p. 1.

34. Somorjai, G.A.; Li, Y. Introduction to Surface Chemistry and Catalysis, 2nd ed.; John Wiley \& Sons: Hoboken, NJ, USA, 2010.

35. Ertl, G. Catalytic Ammonia Synthesis, 1st ed.; Jennings, J.R., Ed.; Plenum: New York, NY, USA, 1991; p. 109.

36. Hoffmann, R. Solids and Surfaces: A Chemist's View of Bonding in Extended Structures, 1st ed.; Wiley-VCH: New York, NY, USA, 1988.

37. Ponec, V.; Bond, G.C. Catalysis by metals and alloys. In Studies in Surface Science and Catalysis, 1st ed.; Elsevier: Amsterdam, The Netherlands, 1995; Volume 95, pp. 7-72.

38. Greeley, J.; Nørskov, J.K.; Mavrikakis, M. Electronic structure and catalysis on metal surfaces. Annu. Rev. Phys. Chem. 2002, 53, 319-348. [CrossRef] [PubMed]

39. Scanlon, M.D.; Peljo, P.; Méndez, M.A.; Smirnov, E.; Girault, H.H. Charging and discharging at the nanoscale: Fermi level equilibration of metallic nanoparticles. Chem. Sci. 2015, 6, 2705-2720. [CrossRef]

40. Flores, F.; Ortega, J. Basic Theory of the Molecule-Metal Interface. In The Molecule-Metal Interface; Koch, N., Ueno, N., Wee, A.T.S., Eds.; Wiley-VCH: Weinheim, Germany, 2011; pp. 17-50.

41. Adams, D.M.; Brus, L.; Chidsey, C.E.; Creager, S.; Creutz, C.; Kagan, C.R.; Kamat, P.V.; Lieberman, M.; Lindsay, S.; Marcus, R.A.; et al. Charge Transfer on the Nanoscale: Current Status. J. Phys. Chem. B 2003, 107, 6668-6697. [CrossRef]

42. Bredas, J.-L.; Beljonne, D.; Coropceanu, V.; Cornil, J. Charge-Transfer and Energy-Transfer Processes in $\pi$-Conjugated Oligomers and Polymers: A Molecular Picture. Chem. Rev. 2004, 104, 4971-5003. [CrossRef] [PubMed]

43. Witte, G.; Lukas, S.; Bagus, P.S.; Wöll, C. Vacuum level alignment at organic/metal junctions: "Cushion" effect and the interface dipole. Appl. Phys. Lett. 2005, 87, 263502. [CrossRef]

44. Kera, S.; Yabuuchi, Y.; Yamane, H.; Setoyama, H.; Okudaira, K.K.; Kahn, A.; Ueno, N. Impact of an interface dipole layer on molecular level alignment at an organic-conductor interface studied by ultraviolet photoemission spectroscopy. Phys. Rev. B: Condens. Matter Mater. Phys. 2004, 70, 085304. [CrossRef]

45. Pearson, R.G. Hard and Soft Acids and Bases. J. Am. Chem. Soc. 1963, 85, 3533-3539. [CrossRef]

46. Ghosh, S.K.; Nath, S.; Kundu, S.; Esumi, K.; Pal, T. Solvent and Ligand Effects on the Localized Surface Plasmon Resonance (LSPR) of Gold Colloids. J. Phys. Chem. B 2004, 108, 13963-13971. [CrossRef]

47. Battocchio, C.; Porcaro, F.; Mukherjee, S.; Magnano, E.; Nappini, S.; Fratoddi, I.; Quintiliani, M.; Russo, M.V.; Polzonetti, G. Gold nanoparticles stabilized with aromatic thiols: Interaction at the molecule-metal interface and ligand arrangement in the molecular shell investigated by SR-XPS and NEXAFS. J. Phys. Chem. C 2014, 118, 8159-8168. [CrossRef]

48. Jiang, P.; Li, S.Y.; Xie, S.S.; Gao, Y.; Song, L. Machinable long PVP-stabilized silver nanowires. Chem. A Eur. J. 2004, 10, 4817-4821. [CrossRef] [PubMed]

49. Vázquez, H.; Qszwaldowski, R.; Pou, P.; Ortega, J.; Pérez, R.; Flores, F.; Kahn, A. Dipole formation at metal/PTCDA interfaces: Role of the charge neutrality level. Europhys. Lett. 2004, 65, 802-808. [CrossRef] 
50. Borodko, Y.; Humphrey, S.M.; Tilley, T.D.; Frei, H.; Somorjai, G.A. Charge-transfer interaction of poly(vinylpyrrolidone) with platinum and rhodium nanoparticles. J. Phys. Chem. C 2007, 111, 6288-6295. [CrossRef]

51. Soe, W.H.; Manzano, C.; de Sarkar, A.; Chandrasekhar, N.; Joachim, C. Direct Observation of Molecular Orbitals of Pentacene Physisorbed on Au(111) by Scanning Tunneling Microscope. Phys. Rev. Lett. 2009, 102, 176102. [CrossRef] [PubMed]

52. Susut, C.; Chen, D.-J.; Sun, S.-G.; Tong, Y.J. Capping polymer-enhanced electrocatalytic activity on Pt nanoparticles: A combined electrochemical and in situ IR spectroelectrochemical study. Phys. Chem. Chem. Phys. 2011, 13, 7467-7474. [CrossRef] [PubMed]

53. Techane, S.D.; Gamble, L.J.; Castner, D.G. Multitechnique characterization of self-assembled carboxylic acid-terminated alkanethiol monolayers on nanoparticle and flat gold surfaces. J. Phys. Chem. C 2011, 115, 9432-9441. [CrossRef] [PubMed]

54. Kronik, L.; Yoshitada Morikawa, Y. Understanding the Metal-Molecule Interface from First Principles. In The Molecule-Metal Interface; Koch, N., Ueno, N., Wee, A.T.S., Eds.; Wiley-VCH: Weinheim, Germany, 2011; pp. 51-89.

55. Lee, L.-H. Molecular Bonding and Adhesion at Polymer-Metal Interphases. J. Adhes. 1994, 46, 15-38. [CrossRef]

56. Stowell, C.A.; Korgel, B.A. Iridium Nanocrystal Synthesis and Surface Coating-Dependent Catalytic Activity. Nano Lett. 2005, 5, 1203-1207. [CrossRef] [PubMed]

57. Tsunoyama, H.; Ichikuni, N.; Sakurai, H.; Tsukuda, T. Effect of electronic structures of au clusters stabilized by poly( $N$-vinyl-2-pyrrolidone) on aerobic oxidation catalysis. J. Am. Chem. Soc. 2009, 131, 7086-7093. [CrossRef] [PubMed]

58. Udumula, V.; Tyler, J.H.; Davis, D.A.; Wang, H.; Linford, M.R.; Minson, P.S.; Michaelis, D.J. Dual optimization approach to bimetallic nanoparticle catalysis: Impact of $\mathrm{M}_{1} / \mathrm{M}_{2}$ ratio and supporting polymer structure on reactivity. ACS Catal. 2015, 5, 3457-3462. [CrossRef]

59. Chen, G.; Xu, C.; Huang, X.; Ye, J.; Gu, L.; Li, G.; Tang, Z.; Wu, B.; Yang, H.; Zhao, Z.; et al. Interfacial electronic effects control the reaction selectivity of platinum catalysts. Nat. Mater. 2016, 15, 564-569. [CrossRef] [PubMed]

60. Kwon, S.G.; Krylova, G.; Sumer, A.; Schwartz, M.M.; Bunel, E.E.; Marshall, C.L.; Chattopadhyay, S.; Lee, B.; Jellinek, J.; Shevchenko, E.V. Capping ligands as selectivity switchers in hydrogenation reactions. Nano Lett. 2012, 12, 5382-5388. [CrossRef] [PubMed]

61. Mitsudome, T.; Kaneda, K. Advanced core-shell nanoparticle catalysts for efficient organic transformations. Chem CatChem 2013, 5, 1681-1691. [CrossRef]

62. Marshall, S.T.; O’Brien, M.; Oetter, B.; Corpuz, A.; Richards, R.M.; Schwartz, D.K.; Medlin, J.W. Controlled selectivity for palladium catalysts using self-assembled monolayers. Nat. Mater. 2010, 9, 853-858. [CrossRef] [PubMed]

63. Kahsar, K.R.; Schwartz, D.K.; Medlin, J.W. Liquid- and vapor-phase hydrogenation of 1-epoxy-3-butene using self-assembled monolayer coated palladium and platinum catalysts. Appl. Catal. A Gen. 2012, 445-446, 102-106. [CrossRef]

64. Zhong, R.Y.; Sun, K.Q.; Hong, Y.C.; Xu, B.Q. Impacts of organic stabilizers on catalysis of Au nanoparticles from colloidal preparation. ACS Catal. 2014, 4, 3982-3993. [CrossRef]

65. Villa, A.; Wang, D.; Veith, G.M.; Vindigni, F.; Prati, L. Sol immobilization technique: A delicate balance between activity, selectivity and stability of gold catalysts. Catal. Sci. Technol. 2013, 3, 3036-3041. [CrossRef]

66. Tao, A.R.; Habas, S.; Yang, P. Shape Control of Colloidal Metal Nanocrystals. Small 2008, 4, 310-325. [CrossRef]

67. Haider, P.; Urakawa, A.; Schmidt, E.; Baiker, A. Selective blocking of active sites on supported gold catalysts by adsorbed thiols and its effect on the catalytic behavior: A combined experimental and theoretical study. J. Mol. Catal. A Chem. 2009, 305, 161-169. [CrossRef]

68. Campisi, S.; Ferri, D.; Villa, A.; Wang, W.; Wang, D.; Kröcher, O.; Prati, L. Selectivity Control in Palladium-Catalyzed Alcohol Oxidation through Selective Blocking of Active Sites. J. Phys. Chem. C 2016, 120, 14027-14033. [CrossRef]

69. Ferri, D.; Mondelli, C.; Krumeich, F.; Baiker, A. Discrimination of Active Palladium Sites in Catalytic Liquid-Phase Oxidation of Benzyl Alcohol. J. Phys. Chem. B 2006, 110, 22982-22986. [CrossRef] [PubMed] 
70. Centrone, A.; Penzo, E.; Sharma, M.; Myerson, J.W.; Jackson, A.M.; Marzari, N.; Stellacci, F. The role of nanostructure in the wetting behavior of mixed-monolayer-protected metal nanoparticles. Proc. Natl. Acad. Sci. USA 2008, 105, 9886-9891. [CrossRef] [PubMed]

71. Reetz, M.T.; Helbig, W.; Quaiser, S.A.; Stimming, U.; Breuer, N.; Vogel, R. Visualization of Surfactants on Nanostructured Palladium Clusters by a Combination of STM and High-Resolution TEM. Science 1995, 267, 367-369. [CrossRef] [PubMed]

72. Chang, S.S.; Shih, C.W.; Chen, C.D.; Lai, W.C.; Wang, C.C. The shape transition of gold nanorods. Langmuir 1999, 15, 701-709. [CrossRef]

73. Kano, S.; Tada, T.; Majima, Y. Nanoparticle characterization based on STM and STS. Chem. Soc. Rev. 2015, 44, 970-987. [CrossRef] [PubMed]

74. Jackson, A.M.; Hu, Y.; Silva, P.J.; Stellacci, F. From Homoligand- to Mixed-Ligand- Monolayer-Protected Metal Nanoparticles: A Scanning Tunneling Microscopy Investigation. J. Am. Chem. Soc. 2006, 128, 11135-11149. [CrossRef] [PubMed]

75. Stöhr, J.; Jaeger, R. Absorption-edge resonances, core-hole screening, and orientation of chemisorbed molecules: CO, NO, and $\mathrm{N}_{2}$ on Ni (100). Phys. Rev. B 1982, 26, 4111. [CrossRef]

76. Stöhr, J. NEXAFS Spectroscopy, 1st ed.; Springer: Berlin/Heidelberg, Germany, 1992.

77. Rogers, S.M.; Dimitratos, N.; Jones, W.; Bowker, M.; Kanaras, A.G.; Wells, P.P.; Catlow, C.R.A.; Parker, S.F. The adsorbed state of a thiol on palladium nanoparticles. Phys. Chem. Chem. Phys. 2016, 18, 17265-17271. [CrossRef] [PubMed]

78. Wu, B.; Huang, H.; Yang, J.; Zheng, N.; Fu, G. Selective hydrogenation of $\alpha, \beta$-unsaturated aldehydes catalyzed by amine-capped platinum-cobalt nanocrystals. Angew. Chem. Int. Ed. 2012, 51, 3440-3443. [CrossRef] [PubMed]

79. Makosch, M.; Lin, W.I.; Bumbálek, V.; Sá, J.; Medlin, J.W.; Hungerbühler, K.; van Bokhoven, J.A. Organic thiol modified $\mathrm{Pt} / \mathrm{TiO}_{2}$ catalysts to control chemoselective hydrogenation of substituted nitroarenes. ACS Catal. 2012, 2, 2079-2081. [CrossRef]

80. Castillejos, E.; Jahjah, M.; Favier, I.; Orejón, A.; Pradel, C.; Teuma, E.; Masdeu-Bultò, A.M.; Serp, P.; Gómez, M. Synthesis of platinum-ruthenium nanoparticles under supercritical $\mathrm{CO}_{2}$ and their confinement in carbon nanotubes: Hydrogenation applications. Chem CatChem 2012, 4, 118-122. [CrossRef]

81. McKenna, F.M.; Anderson, J.A. Selectivity enhancement in acetylene hydrogenation over diphenyl sulphide-modified Pd/ $\mathrm{TiO}_{2}$ catalysts. J. Catal. 2011, 281, 231-240. [CrossRef]

82. Sadeghmoghaddam, E.; Gu, H.; Shon, Y.S. Pd nanoparticle-catalyzed isomerization vs hydrogenation of allyl alcohol: Solvent-dependent regioselectivity. ACS Catal. 2012, 2, 1838-1845. [CrossRef] [PubMed]

83. Chen, K.; Wu, H.; Hua, Q.; Chang, S.; Huang, W. Enhancing catalytic selectivity of supported metal nanoparticles with capping ligands. Phys. Chem. Chem. Phys. 2013, 15, 2273-2277. [CrossRef] [PubMed]

84. Schoenbaum, C.A.; Schwartz, D.K.; Medlin, J.W. Controlling the surface environment of heterogeneous catalysts using self-assembled monolayers. Acc. Chem. Res. 2014, 47, 1438-1445. [CrossRef] [PubMed]

85. Taguchi, T.; Isozaki, K.; Miki, K. Enhanced catalytic activity of self-assembled-monolayer-capped gold nanoparticles. Adv. Mater. 2012, 24, 6462-6467. [CrossRef] [PubMed]

86. Pang, S.H.; Schoenbaum, C.A.; Schwartz, D.K.; Medlin, J.W. Directing reaction pathways by catalyst active-site selection using self-assembled monolayers. Nat. Commun. 2013, 4, 2448. [CrossRef] [PubMed]

87. Kahsar, K.R.; Schwartz, D.K.; Medlin, J.W. Control of Metal Catalyst Selectivity through Specific Noncovalent Molecular Interactions. J. Am. Chem. Soc. 2014, 134, 520-526. [CrossRef] [PubMed]

88. Mallat, T.; Orglmeister, E.; Baiker, A. Asymmetric Catalysis at Chiral Metal Surfaces Asymmetric Catalysis at Chiral Metal Surfaces. Chem. Rev. 2007, 107, 4863-4890. [CrossRef] [PubMed]

89. Tai, A.; Sugimura, T. Chiral Catalyst Immobilization and Recycling; de Vos, D.E., Vankelecom, I.F.J., Jacobs, P.A., Eds.; Wiley-VCH: Weinheim, Germany, 2000; p. 173.

90. Mallat, T.; Baiker, A. Selectivity enhancement in heterogeneous catalysis induced by reaction modifiers. Appl. Catal. A Gen. 2000, 200, 3-22. [CrossRef]

91. Vargas, A.; Bürgi, T.; Baiker, A. Adsorption of cinchonidine on platinum: A DFT insight in the mechanism of enantioselective hydrogenation of activated ketones. J. Catal. 2004, 226, 69-82. [CrossRef]

92. Jansat, S.; Gómez, M.; Philippot, K.; Muller, G.; Guiu, E.; Claver, C.; Castillón, S.; Chaudret, B. A case for enantioselective allylic alkylation catalyzed by palladium nanoparticles. J. Am. Chem. Soc. 2004, 126, 1592-1593. [CrossRef] [PubMed] 
93. Yasukawa, T.; Miyamura, H.; Kobayashi, S. Polymer-incarcerated chiral Rh/Ag nanoparticles for asymmetric 1,4-addition reactions of arylboronic acids to enones: Remarkable effects of bimetallic structure on activity and metal leaching. J. Am. Chem. Soc. 2012, 134, 16963-16966. [CrossRef] [PubMed]

94. Gross, E.; Liu, J.H.; Alayoglu, S.; Marcus, M.A.; Fakra, S.C.; Toste, F.D.; Somorjai, G.A. Asymmetric catalysis at the mesoscale: Gold nanoclusters embedded in chiral self-assembled monolayer as heterogeneous catalyst for asymmetric reactions. J. Am. Chem. Soc. 2013, 135, 3881-3886. [CrossRef] [PubMed]

95. Weng, Z.; Zaera, F. Increase in activity and selectivity in catalysis via surface modification with self-assembled monolayers. J. Phys. Chem. C 2014, 118, 3672-3679. [CrossRef]

96. Angioletti-Uberti, S.; Lu, Y.; Ballauff, M.; Dzubiella, J. Theory of Solvation-Controlled Reactions in Stimuli-Responsive Nanoreactors. J. Phys. Chem. C 2015, 119, 15723-15730. [CrossRef]

97. Amsden, B. Solute Diffusion within Hydrogels. Mechanisms and Models. Macromolecules 1998, 31, 8382-8395. [CrossRef]

98. Horecha, M.; Kaul, E.; Horechyy, A.; Stamm, M. Polymer microcapsules loaded with Ag nanocatalyst as active microreactors. J. Mater. Chem. A 2014, 2, 7431-7438. [CrossRef]

99. Wu, S.; Dzubiella, J.; Kaiser, J.; Drechsler, M.; Guo, X.; Ballauff, M.; Lu, Y. Thermosensitive Au-PNIPA yolk-shell nanoparticles with tunable selectivity for catalysis. Angew. Chem. Int. Ed. 2012, 51, 2229-2233. [CrossRef] [PubMed]

100. Dai, Y.; Liu, S.; Zheng, N. $\mathrm{C}_{2} \mathrm{H}_{2}$ Treatment as a Facile Method to Boost the Catalysis of Pd Nanoparticulate Catalysts. J. Am. Chem. Soc. 2014, 136, 5583-5586. [CrossRef] [PubMed]

(C) 2016 by the authors; licensee MDPI, Basel, Switzerland. This article is an open access article distributed under the terms and conditions of the Creative Commons Attribution (CC-BY) license (http:/ / creativecommons.org/licenses/by/4.0/). 